\title{
XII. Memoir relative to the annular eclipse of the sun, which will happen on September 7, 1820
}

\section{Francis Baily}

To cite this article: Francis Baily (1820) XII. Memoir relative to the annular eclipse of the sun, which will happen on September 7, 1820, Philosophical Magazine Series 1, 55:262, 85-102, DOI: 10.1080/14786442008652281

To link to this article: http://dx.doi.org/10.1080/14786442008652281

曲 Published online: 29 Jul 2009.

Submit your article to this journal

Џ Article views: 2 
gratification is the reflection of having been a zealous promoter of mathematical science for upwards of sixty years, as a teacher, chiefly at the Royal Military Academy at Woolwich; as a laborious contributor to the Philosophical Transactions, and an Editor of that work; as the conductor of certain scientific Journals which have met with great encouragement ; and also as the-anthor of several successful publications on mathematical subjects.

" If I feel this satisfaction in a retrospect of laborious application in the zealous pursuit of those elementary sciences, which lead to the knowledge of the Principia and other works of our inmortal Newton; how much more gratifying must your reflections be, in having so ably illustrated as well as honoured our great anthor, and carried his discoveries higher than perhaps he himself conld have ever contemplated!

"That you may long enjoy this gratification, and continue to enlarge the boundaries of science, is the sincere wish of

"Your most obedient and faithful servant, "Charlis Horros",

To the Marquis de Laplace.

XII. Memoir relative to the Annular Eclipse of the Sun, which will happen on Septemler 7, 1820. By Francis Baily.

T

$\boldsymbol{\Gamma}_{\text {HE }}$ solar eclipse which will happen on Thursday, September 7, 1820 , will be the greatest of all those which have happened in this part of Europe ever since the year 1764; and indeed of all those which will again happen here before the year 1817. Like the two eclipses above alluded to, it will be annular: that is, the disc of the moon will not wholly cover the disc of the sun ; but, in certain parts of the earth, the sun will show the appearance of an annulus, or ring, round the body of the moon; the position and magnitude of which will depend on the situation of the spectator. In no part of Eugland, however, will this annular appearance he observed * : but, on the continent, in any part of that tract of country which extends nearly in a straight line from the north of Westphalia to the south of Italy, the inhabitants will have an opportunity of beholding this singular phænomenon.

Annular eclipses do not appear to have been noticed by the ancients, who probably confounded them with partial ones. Indeed, the only authentic accounts of any well observed annular eclipses in this part of Europe (besides the one in 1764 above mentioned) are those of February 18, 1736-7 and of July 14,

* The eclipse however will be annular in the Shetland islands : and it will be of considerable magnitude along the whole eistern coast of Great Britain. 
$1748 *$; the former of which was observed by the celebrated Colin Maclaurin at Edinburgh, and the latter by the Earl of Morton and Mr. Short at Aberdour Castle near the same place. Indeed the annular appearance of the eclipse of 1737 was confined principally to Scotland: and the eclipses of 1748 and 1764 , althongh visible to a great part of Europe, were not so generally observed as could be wished on account of the badness of the weather; so that we have not any very considerable degree of information respecting this kind of solar eclipses. Moreover at those periods the lunar tables were so defective that it could not be predicted, with any degree of accuracy, where the annular appearance would be visible : so that many valuable observations were probably lost on that account. "This difficulty however is in a great nieasure removed by late improvements not only in the lunar tables, but likewise in the analytical investigations relative to the calculation of eclipses; although the computations are still very laborious and troublesome.

Prior to the total eclipse, which took place in London in the year 1715 , Dr. Halley published an account of the path of the moon's shadow across the island of Great Britain; and called on the inhabitants to note down their ohservations and forward them to him, in order that he might afterwards compare them, and thereby correct the elements made use of in the calculation of eclipses. The good effect of this measure may be seen in the Report which that illustrious astronomer afterwards drew up and sent to the Rioyal Society, and which is inserted in the Philosophical Transactions, No. 343, vol. xxix. page 245. Mr. Maclaurin, likewise, previons to the annular eclipse in 1737 before mentioned, wrote to several persons in the country, " desiring that they would determine and note down the duration of the annular appearance as exactly as possible; in hopes, by comparing their observations, to have traced more correctly the path of the centre and limits of the phænomenon." And in 1748 Mr. Alexander Munro (Professor of Anatomy of Edinburgh) by Mr. Short's desire wrote to all his friends in different parts of the country, to prepare in the best manner they could for the most exact observation of the annular eclipse which was about to take place in that year. And he regrets that he did not make this application earlier; for he remarks that had "my request of having the duration of the annular appearance measured been made more public before the eclipse (after Dr. Halley's example in 1715) I doubt not but I should have been able to have given a more exact

* See a detailed account of these eclipses, and of the phænomena attending them, in the Philosophical Transactions, vol. xl. page 177, and yol. xlv. page 582 .

account 
account of the progress of the centre of this phænomenon and of its limits." M. De L'isle also, with a similar view, published a notice to astronomers* in order, as he observes, " exciter les curieux de l'Europe, qui pourront voir l'éclipse annulaire yui doit arriver, d'y apporter toute l'attention possible, et de faire, de bonne heure, tontes les dispositions nécessaires pour la bien observer; afin de nous procurer tous les avantages que l'on en peut retirer pour l'astronomie, la géographie, et la physique."

It is worthy of remark that this eclipse (1748) was the first that the celebrated Lalande (to whom the astronomical world is so much indebted) ever saw. He was then only 16 years of age : and the impression, which it made on him, fixed his future pursuits in life, and induced him to become an astronomer. It indeed excited so much attention in Europe that the King of France (Louis XV) went purposely to Compiegne in order to observe it, attended by the Abbé Nollet, and Messrs. De Thury and De La Condamine; and furnished with every convenient instrument for the purpose. The royal astronomer there made several important observations + . M. Lemonnier likewise undertook the journey from Paris to Ediuburgh, furnished with proper instruments, purposely to observe it, during its annular appearance : and he afterwards published some important remarks thereon $\uparrow . M . D e$ L'isle, abovementioned, published also a paper on the subject entitled Nouvelle théorie des éclipses, founded entirely on the recent observations that had been made $\S$. M. Pingré afterwards added very considerably to these refections in his interesting memoir, entitled Recherches sur la longitude des plusieurs villes \|. Mechain likewise made a great many calculations relating to it, from the manuscript collections of M. De L'isle. But it was reserved to Lalande, fifty years after the event, to deduce the most important conclusions from this singular phænomenon, in his paper Sur la grande éclipse annulaire de 17489 .

Considering therefore the interest which has always been attached to this kind of phænomena, and the important couclusions to be drawn from them, I was somewhat surprised to find that no particular notice has been taken of the ensuing eclipse either

* Avertissement aux astronomes sur l'éclipse annulairs du soleil gine l'ox ettend $l c 25$ Juillet 1748 . It was published, however, only three months prior to the eclipse taking place: so that there was searcely time for it to get ir to general circulation.

+ The same monarch had also made several observations on the eclipse of 1737 at Versailles, attended by the celebrated Cassini.

+ See the Mímoires de l'Acad. Roy. des Sréences for 1765, page 463.

5 Ibid for 1757 , page 490 . II Ibial for 1766 , page 17 .

of See .Hémoires de l'Institut. (Scien. Math. et Phy.) vol. ii. page 364- 
in the Connaissance des Tems, or in the Nautical Almanac: but that it is merely announced there in the usual formal manner, without a single remark on the occasion. It is true that $M$. Bode, in his ephemeris published at Berlin, has given (as usual) a general outline of the eclipse together with a map descriptive of the phases: but he has not called on the inhabitants to look out for this phænomenon, nor drawn their attention to any of the subjects which it is most desirable they should observe. In order to supply this defect, as far as my humble efforts will avail, I have drawn up the following memoir, under the hope that it may induce others, who have more leisure and are at the same time more conversant with the subject than myself, to pursue the inquiry, and suggest further hints to those who may have an opportunity of observing this rare phænomenon.

M. De L'isle, in his Avertissement above alluded to, respecting the eclipse of 1748, suggested the advantage and propriety of some scientific person, in the principal states of Europe through which the shadow of the moon's umbra passed, undertaking to announce to the inhabitants the several observations which it would be proper for them to make; and afterwards to collect and arrange such observations for further investigation, if sufficiently convinced of their accuracy. A similar plan might be adopted in the present instance; and, from the more general diffusion of science, would be more likely to be attended with a beneficial effect. Such collections of observations (when made) should be sent by the different collectors to one or more of the principal astronomers of Europe, in order that they might be finally investigated, and the result laid before the public.

With that view I would take this opportunity of requesting those, into whose hands the present memoir may fall, to circulate it as much as possible on the continent; and amongst those persons who, from their connection with any foreign literary journal, may be likely to diffuse the subject of it amongst the inhabitants of that part of Europe and Africa where the annular appearance will be cbserved. Such of our own countrymen likewise, that may be travelling in any of the provinces on the continent here alluded to, will promote the interest of astronomy if they would carefully note down or collect any of the circumstances hereinafter alluded to, or indeed any other remarkable phrenomena that may happen during this eclipse. I shall be happy to receive any observations of this kind that may be forwarded to me, and will preserve the result of them, as above proposed, for a future investigation.

The elements of the present eclipse I have computed from M. Burckhardt's tables of the moon and M. Delambre's tables 
of the sun: and they are as follow. The ecliptic conjunction will take place on September 7, 1820, at

$\left.\begin{array}{l}1^{\text {h }} .51^{\prime} .37^{\prime \prime}, 3 \text { P.M. apparent time } \\ \text { or } \\ \text { 1. } 49.26,2 \text { P.M. mean time }\end{array}\right\}$ at Greenwich:

And, at that time, we shall have the

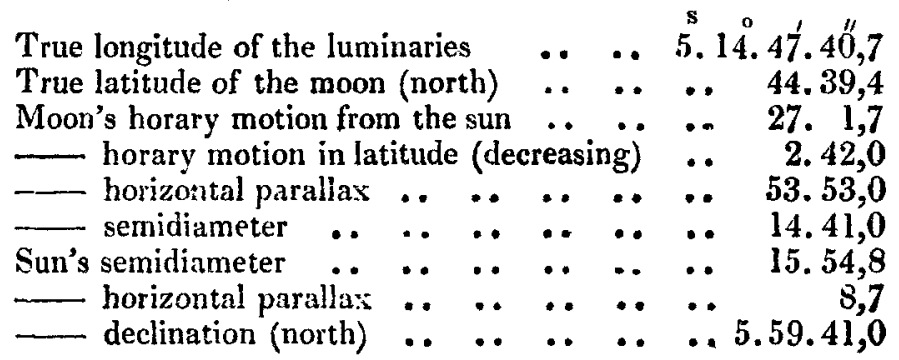

From these elements it may be determined that the moon's shadow first touches the earth's disc at $1 \mathrm{l}^{\mathrm{h}} \cdot 23^{\prime}$ A.M. apparent time at Greenwich, in N. lat. 59 $.43^{\prime}$, W. long. $90^{\circ} .50^{*}$; and that it finally leaves it at $4^{\text {h }} .39^{\frac{3}{4}}$ P.M. apparent time at Greenwich in N. lat. $3^{\circ} \cdot 21^{\prime}$, E. long. $20^{\circ} .25^{\prime}$. Consequently the total duration of the general eclipse to the inhabitants of the earth will be about $5^{\mathrm{h}} .17^{\prime}$ : but, at no one place in particular will the duration be much more than half that time.

The central path of the moon's shadow across the earth's disc, which is the most material circumstance in inquiries of this nature (since it serves to point out those parts of the world where the eclipse will be seen annular) may be determined with considerable accuracy from the principles laid down by M. Delambre in his Traité d'Astronomie (vol. ii. page 384) : and, agreeably to the formule which he has there given, I have carefully computed the following table, which shows the several points (expressed by positions of latitude and longitude) through which the centre of the moon's shadow will pass in its progress across the earth's dise, at the several times therein mentioned. The first column denotes the apparent time at Greenwich, at the moment when the centre of the moon's shadow passes the given points laid down in the second and third columns : and the last column shows the sorresponding apparent time at those places.

* All the Longitudes in this memoir are rcckoned from the meridian of Greenwich. 
Memoir relative to the Ainnular Eclipse of the Sun,

\begin{tabular}{|c|c|c|c|}
\hline $\begin{array}{c}\text { Apparent time } \\
\text { at Greenwich. } \\
\text { P.M. }\end{array}$ & $\begin{array}{l}\text { Latitude } \\
\text { North. }\end{array}$ & $\begin{array}{l}\text { Longitude } \\
\text { from Greenwich. }\end{array}$ & $\begin{array}{l}\text { Apparent time at } \\
\text { the place. }\end{array}$ \\
\hline 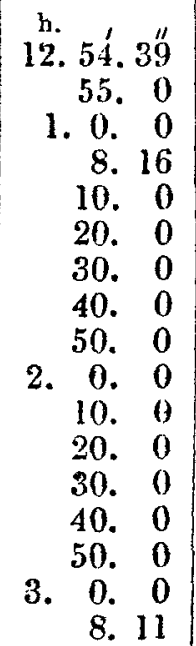 & $\begin{array}{l}81.39 .29 \\
83.39 .34 \\
82.24 .34 \\
76.6 .21 \\
75.23 .11 \\
69.9 .41 \\
64.13 .27 \\
59.47 .31 \\
55.44 .40 \\
51.56 .26 \\
45.18 .42 \\
44.49 .25 \\
41.25 .32 \\
38.3 .53 \\
34.40 .41 \\
31.7 .19 \\
27.10 .30\end{array}$ & $\begin{array}{rr}W .149 .32 .55 \\
129.44 .37 \\
42.38 .12 \\
17.3 .15 \\
14.31 .41 \\
5.52 .11 \\
0.46 .50 \\
2.50 .42 \\
\text { 5. } 48.32 \\
8.26 .4 \\
10.57 .6 \\
13.32 .32 \\
16.23 .32 \\
19.44 .0 \\
23.59 .43 \\
30.24 .13 \\
46.2 .4\end{array}$ & $\begin{array}{l}\text { b. } 2.56 .27 \text { А.M } \\
\text { 4.16. } 2 \\
10.9 .27 \\
12.0 .0 \\
12.11 .53 \text { Р.M. } \\
\text { 12. } 56.31 \\
1.26 .53 \\
1.51 .23 \\
2.13 .14 \\
2.33 .44 \\
2.53 .48 \\
3.14 .10 \\
3.35 .34 \\
3.58 .56 \\
4.25 .59 \\
5.1 .37 \\
6.12 .19\end{array}$ \\
\hline
\end{tabular}

From this table it will be seen that the central eclipse commences in N. lat. $81^{\circ} .39^{\prime} .29^{\prime \prime}$, W. long. $149^{\circ} .32^{\prime} .55^{\prime \prime}$, when the sun and moon will rise together (the centre of the moon being directly on the centre of the sun's disc) to the inhabitants of that part of the globe, at $2^{\text {h }} .56^{\prime}, 27^{\prime \prime}$ in the morning, corresponding to $12^{\mathrm{h}} .54^{\prime} .39^{\prime \prime}$ (or $0^{\mathrm{h}} .54^{\prime} .39^{\prime \prime *}$ ) in the afternoon at Greenwich : that the sun will be centrally eclipsed on the meridian (or exactly at noon) in N. lat. $76^{\circ} .6^{\prime} \cdot 21^{\prime \prime}$, W. long. $17^{\circ}$ $3^{\prime} 15^{\prime \prime}$, when it is $1^{\mathrm{h}} .8^{\prime} \cdot 16^{\prime \prime}$ in the afternoon at Greenwich: and that the sun will set centraily eclipsed in N. lat. $27^{\circ} .10^{\prime} .30^{\prime \prime}$, E. long. $46^{\circ} .2^{\prime} .4^{\prime \prime}$ at $6^{\text {h }} \cdot 12^{\prime} .19^{\prime \prime}$ in the afternoon, corresponding to $3^{\text {h }} .8^{\prime} .11^{\prime \prime}$ at Greenwich.

If the points, mentioned in the second and third columns of the above table, be marked on a good map, and lines be drawn connecting these points, we shall have the path of the centre of the moon's shadow across the globe. Whence it will be seen that the centre of the shadow, having entered the earth's disc

* That is, 54'.39" after 12 o'clock at noon. The English astronomers be gin the day at noon; but the French reckon from midnight, as in the civil mode of reckoning. There cannot however be any ambiguity, in the present case, as to the $12^{\mathrm{h}}$. 
mear the north pole*, will proceed between the Shetland islands and the const of Norway down the north sea, and enter the continent of Europe on the coast of Westphalia, about half way between the Ems and the Weser. It will thence proceed, nearly in a straight line, across Germany and the Tyrol country, and enter the guif of Venice abont midway between Trieste and Venice. Traversing that gulf it will cross the heel of Italy; and, after skirting the coast of the Morea and Candia, will pass directly over Alexandria in Egypt; and finally leave the earth in Arabia near the Persian gulf.

If we set off two other lines on the map, parallel to this central line, one on each side thereof, and each at the distance of ahout 130 geographical miles from the central line, the intermediate space between these two boundary lines will nearly $\uparrow$ represent the path of the moon's umbra; and will show all those places where the eclipse will be seen annular, or where the whole body of the moon will appear on the face of the sun. Some uncertainty, however, may exist with respect to those towns which are situated near the borders of the umbra, such as Rotterdam, Aix la Chapelle, Liege, 'Treves, Freyburg, Parma, Rome, and other places on the one side; and Magdeburg, Leipsic, Ragusa, $\Lambda$ thens, and other places on the other side of the central path: since the eclipse may or may not be annular in the neighbourhood of those towns according to circumstances. Nevertheless, at all those places, and indeed to the whole of Europe and to a great part of Asia and Africa, the eclipse will be visible ; differing only in magnitude according to the situation of the spectator. But, in no part will it be annular except at those places which are situated within the limits of the umbra, as above mentioned f.

Those persons, who happen to be situated on the western border of the umbra, will, at the time of the middle of the eclipse, see the upper limb of the moon in contact with the upper limb of the sun; and consequently the unobscured portion of the sun's disc will be seen round the under part of the moon. On

* It will traverse the supposed polar basin, and the north east coast of Greenland, the object of so much laudable curiosity at the present moment: so that if the adventurous nevigators to those parts should not have returned before the date of this eclipse, they will probably observe it in those high iatitudes.

+ It must be evident to those acquainted with the principles of astronomy that the umbra will not be exactly of the same width in any two points of its course; but will be constantly varying. It will not, however, undergo any material alteration in its progress across the continent of Furope.

$\ddagger$ For a general view of the path of the urnbra across the continent of Europe, see Piate II. 
the contrary, those persons who are on the eastern confines of the umbra will see the lower limb of the moon in contact with the lower limb of the sun. Whilst, to those who are stationed directly in the central path, the centres of the sun and the moon will appear exactly to coineide; and an uniform luminous ring, equal in breadth to about one twenty-ninth part of the sun's diameter, will surround the body of the moon*.

As there are no two points on the face of the globe where the visible appearances of any solar eclipse are exactly alike, it would be an endless task to compute the phænomena for any consider. able number of places : and the usual mode, amongst astronomers, is to give a general outline of the path of the moon's shadow, and to calculate the particular circumstances of the eclipse for the metropolis only, or for some known observatory ; which calculation may be easily adapted to other parts of the kingdom, The notices which are given in the various ephemerides, on this point, are merely for the purpose of informing astronomers to look out for, and note down these phænomena: and the observations, thus made, are afterwards collected and compared together. Under these circumstances the reader must not expect to find the exact time and appearances of this eclipse computed for every place on the continent. It will be sufficient for his purpose if he knows at what time of the day he ought to look out for its commencement; and at what point of the sun's disc he ought to fix his attention in order to observe the first point of contact. The following table will show nearly these several particulars for the different places therein mentioned; and will assist the observer in his computations for any other place within the umbra. These values are deduced merely from a projection of the eclipse, and are consequently given as approximations only, and by no means as the exact values. For, where it is required to have the time true to the nearest second, the observer must calculate the phases of the eclipse for the precise spot where he happens to be stationed.

The angles from the vertex are all reckoned on the right hand side of the sun; as the moon always makes the first impression on the sun's disc, on that side.

* The sun will be elevated, on that day, above the horizon about 34 degrees, to that part of the continent, over which the centre of the moon's umbra passes: consequently the increase of the moon's semidiameter will be about 7 s seconds. 


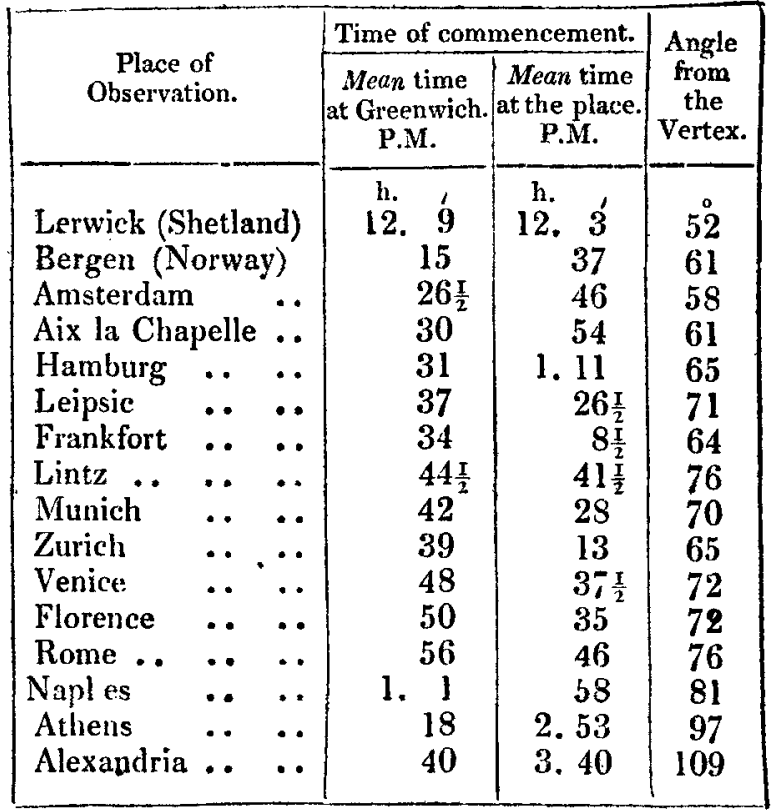

The whole duration of the eclipse will, at all these places, be rather more than two hours and three quarters. But the duration of the annulus will not, in any place, exceed six minutes: and, in some places (at the confines of the umbra) it will be momentary. The nearer the spectator happens to be to the centre of the path of the moon's umbra, the longer will the annular appearance continue.

Having thus given a general outline of this eclipse, I shall proceed to state the principal phænomena which have heen observed in former eclipses of this kind ${ }^{*}$, whereby the reader may be aware of the principal observations to which it will be proper for him to attend, and make his preparations accordingly. Many of these phænomena have given rise to much discussion, and are far from being accurately determined, or reduced to general principles. There is also a degree of doubt respecting the existence of some of them. Those persons therefore who are furnished with convenient instruments, and have a favourable opportunity, should carefully attend to, and note down, not merely the phases of the eclipse but such other appearances as may present them-

* Those of 1737 and 1748 . 'There are but few abscrvations of the eclipse of 1764 


\section{Memoir relative to the Annular Eclipse of the Sun}

selves. It is only by multiplying observations of this kind that we can ultimately arrive at the truth: and an annular eclipse is so rare an occurrence in this part of the globe, that it is hoped every advantage will be taken of it, to improve and advance the connected sciences of astronomy and geography.

There is one important observation however connected with this eclipse, which it is in the power of almost any competent person to make, without the aid of any particular instruments : I allude to the formation and dissolution of the annulus*. This may be determined very accurately, if not by the naked eye, at least with a telescope of very small magnifying power $\dagger$; furnished with a coloured glass to keep off the rays of the sun, or with a glass smoked in the manner hereatter mentioned $\downarrow$. The times of these phases may be determined with sufficient accuracy by means of a clock, or watch that beats seconds; and which should, if possible, be set to mean time on the day of the eclipse. The neglect of this precaution, however, should not prevent the observer from noting down the duration of the annular appearance; which will be the same, whether the wateh is right or not $\$$. As the method therefore of observing this phænomenon is so simple and easy, it is hoped that no person, to whom the opportunity may occur, will omit to note down the particulars; or fail to communicate the same to some person conversant with the subject of astronomy. It will be of equal importance to know that the existence of the annulus is only momentary : or even that it is nearly, but not completely formed $\|$.

Although the possession of proper instruments must give a superior degree of credit to the observations of any person; yet I would

* The annulus is considered as completely formed when the whole body of the moon just appears on the disc of the sun, however unequal in breadth the uncovered part of the sun's disc may be. It is considered as dissolved the moment the moon again touches the concave circumference of the sun's dise. The duration of the annulus will not in any place, as already observed, exceed six minutes, and in some places will be momentary.

$\uparrow A$ common opera glass might be made use of, if nothing better should present itself: as no method should remain untried for determining this very important phase. If the observer be near-sighted, and have not the advantage either of telescope or concave glasses, he may view the sun through a small hole made in a card by means of a pin.

\$ Those, who cannot procure either coloured or smoked glass, may view the image of the sun in a bucket of water, or a vessel filled with oil, placed in a situation where it may not be agitated by the wind.

Should the observer be in such a situation as not to have the advantage of either a clock, or a watch beating seconds, he might easily make a temporary pendulum, of any convenient length, and notice the number of vibrations which it makes during the existence of the annulus. In such case, the length and substance of the pendulum should be specified.

II To those who are not much conversant with practical astronomy, it may perhaps be proper to remark, that the more numerous these coservations 
would not discourage those who have not this advantage, from communicating any circumstances that may occur. For it has been justly observed by $M$. De L'isle, that although no great dependance can be placed on those observations which are not made with a telescope, \&ic. yet that such observations as are made with the naked eye ought not to be entirely neglected; since it affords ns an opportunity of judging of the accuracy of those observations which were made before telescopes, \&c. were invented.

Those persons, however, who nave the proper instruments, and every conveniency for observing, will of course note down the usual circumstances in such case: viz.

1. The time of the commencement of the eclipse*;

2. The time of the formation of the annulus;

3. The time of the dissolution of the annulus + ;

4. The time of the end of the eclipse.

If there should be any spots on the sun, it will be proper (previous to the commencement of the eclipse) to make a diagram of the sun's dise; and to note down the times when the body of the moon comes in contact with the spots, and likewise the times when they again become visible. All these may be determined with sufficient accuracy by the assistance of a telescope magnifying thirty or forty times; together with a well regulated clack or watch that beats seconds; and which, if possible, should as

may be (that is, the greater the number of places where they are made), the more important will be the consequences to be derived from them. Consequently enery observation will be material. Those persons who may observe the eclipse in the country, should state the distance and position of such place from the nearest principal town.

* It is rather difficult to determine the exact time of the commencement of any solar or lunar eclipse; since the impression on the disc does not become visible till some seconds after the eclipse has begun. The field of the telescope should take in at least one-half of the circumference of the sun's dise (taking that portion of it, which may leave the expected point of contact in the centre), as the eye can much better judge of any impression made upon a large, than a small, portion of a circle. In some cases however a wery powerful telescope (which takes in only a small portion of the sun's disc) may be attended with adrantage, as in the case of the solar tclipse on Segtember 5, 1793, where Sir Wm. Herschel observed that the first impression on the sun's disc was made by the projection of two high mountains of the moon, having the appearance of horns; which were distinctly visible on the sun's disc before the body of the moon appeared.-Phil. Trans. 1794, p. 23.

+ In order to determine, with greater accuracy, the formation and dissolution of the annulus, the observer should take into his telescope that part only of the disc of the sun which is necessary for the purpose. By adopting this method Mr. Maclaurin, in 1737, was enabled to observe the appeararce alluded to in page 98 ; and which preceded the perfect formation of the a?!nulus about twerty seconds : thereby enabling him to look out for and note down the exact time, with greater precision. 
before observed be set to mean time on the day of the eclipse*. $I$ must again repeat however, that the neglect of this precaution should not deter the observer from noting down the duration of the several phases above mentioned, and particularly the times at which the annulus is formed and dissolved: which may be afterwards compared with more exact observations, and lead to a correction of the true timest.

It is presumed that the observer will also, from time to time, during the progress of the eclipse, observe and note down the distance and inclination of the cusps in the usual mannerf. It may likewise be proper to remark that it will be of considerable importance to ascertain, at the time of the middle of the eclipse, the magnitude of the annulus on the north and on the south side of the moon, in order to determine how far distant, at that time, the centre of the moon is from the centre of the sun $\xi$. If at the same moment the observer can determine the diameter of the sun and moon, it will add considerably to the importance of the observation; and tend to determine a much disputed point in practical astronomy $\|$. These observations however should be made with a good telescope furnished with an accurate micrometer: and, in making a report thereof, the observer should describe the kind of telescope made use of, as well as the method employed in determining the magnitude of the annulus, \&c. For the sake of

* In the evening of the same day on which this eclipse takes place there will be an eclipse of the first satellite of Jupiter: the immersion will take place at Greenwich at $8^{\text {h }} .34^{\prime} .34^{\prime \prime}$ mean time. Those persons therefore who are furnished with sufficiently powerful telescopes, may (if the weather prove favourable) have an opportunity of ascertaining the correctness of their clocks or watches.

$+M$. De L'isle states, that if we observe the situation of the cusps, or only their distance, at the time of the middle of the eclipse (when the eclipse is not annular, but nearly so), it will serve to determine the apparent route of the penumbra and its limits, as exactly as if we had observed the duration of the annular eclipse.

I There are two modes of observing the phases of an eclipse of the sun: the one, by looking directly at the sun, with a telescope furnished with a micrometer: the other, by receiving the image of the sun, through a telescope, on a screen, in a dark chamber, or camera obscura. Each has its advantages, and may be practised according to circumstances. See Lalande's Astronomie, vol. ii. p. 659. M. De L'isle indeed says that "we may determine, with sufficient exactness, the situation of the cusps, without making use either of the dark chamber or the micrometer, by observing the moment of the passage of the cusps and of the limbs of the sun, by means of simple wires placed in the focus of the telescope, in any situation whatever; and leaving the telescope in a fixed position, during the time that the sun employs to traverse the field of it."

$\$$ M. De L'isle doubts whether this part of the observation can be made with sufficient accuracy in a dark chamber; on account of the indistinctness of the image of the moon.

II See pages 97 and 98 .

greater 
greater accuracy, he shonld also make a diagram of the appearance of the sun and moon, at the time of the middle of the eclipse; placing a mark against that part of the sun's disc which appears the most vertical to him. The point on the circumference of the sun's disc (relative to its vertical or horizontal diameter) where the moon leaves it in order to form the annulus, and again where it touches it at the time of the dissolution of the annulus, should also, if possible, be distinctly noted. M. Le Monnier considers this of considerable importance*.

It was observed, in the annular eclipse of 1737, that the annulus was formed and dissolved very suddenly. For when the whole body of the moon had entered on the disc of the sun, the last portion that entered appeared to adhere to the concave circumference of the sun's disc for some seconds; and the moon appeared elongated on that side, till the sun's light suddenly broke round it, when the moon reassumed its regular curvature. In a similar manner, when the disc of the moon approached the concave line of the sun's disc on the other side, they seemed to run together like two contiguous drops of water on a table, when they touch each other.

It was also observed, in the eclipse of 1737 , " that, as the annulus was forming, the light appeared to break in several irregular spots near the point of contact: and that the limb of the moon seemed to be indented there." These irregular parts seemed likewise to have a kind of motion; although there was no undulation at the same time in the circumference of the sun. Such appearances of a tremulous motion, in certain periods of solar eclipses, are mentioned by Hevelius and others. It was noticed also in the eclipse of $1748 \uparrow$.

In both these eclipses as well as in that of 1764 it was observed that, when the annulus was formed, the moon appeared much smaller on the sun than it really ought to be : and indeed much smaller than the calculations seemed to warrant. But

* In his paper Sur l'utilité des éclipses de soleil (wherein he has drawn many important consequences from the eclipse of 1748 ) he remarks, respecting the method of determining the limits of the umbra, that "la plupart des observateurs, en pareil cas, suivent les routes ordinaires, et n'ont jamais fait assez d'attention au point de la circonférence du limbe du soleil où se forment les ruptures de l'anneau : desormais ces points de la circonférence du disque du soleil seront les plus importans, et nous fourniront les limites que nous voudrons bien assigner."-Mem. de l'Acad. des Sciences for 1765 , page 463 .

+ The Rev. Mr. Irwin, who noticed the eclipse of 1748 at Elgin, says that “ the formation and breaking of the annulus were sensibly to be observed, and passed in a moment; affording a very pleasing sight by the irregular tremulous spots of the sun."-Phil. Trans. vol. xlv. page 595 .

Vol. 55. No. 262. Fel. 1820.

G

whether 
whether this phænomenon arises from an apparent enlargement of the sun's disc, or from an apparent diminution of the moon's disc, or from both, does not seem clearly decided. M. Du Séjour has discussed this subject, with his usual ability, in his Traite analytique des mouvemens appurens des corps célestes, vol. i. page $405,8 c .:$ but he has not come to any precise determination thereon. The observations have not been marle with sufficient accuracy, nor are they sufficiently numerous to enable us to determine so nice an element in the calculation of eclipses. It is hoped therefore that the attention of astronomers will be more drawn towards this subject in the ensuing eclipse *.

In the eclipse of 1737 , Maclaurin observes that about 20 seconds " before the annulus was complete, a remarkable point or speck of pale light appeared near the middle of the part of the moon's circumference that was not yet come upon the disc of the sun : and a gleam of light, more faint than that point, seemed to extend from it to each horn."

In the eclipse of 1748 , it was noticed that there was, "about the middle of the eclipse, a remarkably large spot of light, of an irregular figure and of a considerable brightness, about $7^{\prime}$ or $8^{\prime}$ within the limb of the moon." Mr. Short states that this eclipse was not quite annular at Aberdour Castle: the cusps seemed to wast about one-seventh of the moon's circumference to be joined, yet a brown light was plainly observed both by my Lord Morton and myself to proceed or stretch along the circumference of the moon, from each of the cusps, about one-third of the whole distance of the cusps from each cusp; and there remained about one-third of the whole distance of the cusps not enlightened by this brown light." - " I observed at the extremity of this brown light, which came from the western cusp, a larger quantity of light than in any other place, which at first surprised me; but afterwards I imagined it must have proceeded from some cavity or valley made by two adjoining mountains on the edge or limb of the moon. I had often formerly observed mountains on the circumference of the moon, more or less every where round it, but never saw them so plain as during the time of this eclipse. The mountainous inequalities on the southern limb of the moon were particularly remarkable ; in some parts mountains and valleys alternately; others extended a considerable way along the

* See Lalande's Astronomie, vol. ii. page 445; Delambre's Astronomie, vol. ii. page 423; and also M. Le Monnier's memoir Sur les éctipses totales dus soleil, in the Mem. de IAcad: des Sciences for 1781, page 243 . In this memoir there is a map of the path of the moon's umbra in the total edipse of May ${ }^{\prime} \frac{I}{2}, 1724$, and which appears to have proceeded over great part of England: nevertheless I cannot find any observation of it in this country.

circumi- 
circumference and ended almost perpendicularly like a precipice. My Lord Morton was able to see them very easily through his small reflector."

The king of France, who (as already mentigned) went purposely to Compiegne to observe this eclipse, discovered towards the middle of the eclipse (which was not more than $9 \frac{1}{2}$ digits) " sur la surface de la lune, comprise entre les cornes du soleil, des rayons de lumière rouges, et un filet de lumière qui sembloit masquer le disque de la lune, et qui s'étendoit à une distance des cornes *."

M. De L'isle, in his publication above alluded to, seems to think that a quick eye, guarded with a sufficiently dark glass, might in solar eclipses discover the body or limb of the moon seven or eight minutes before it tonched the sun, and also for the same time after it had left it and was entirely off the sun. He remarks that the observer should defend himself as much as possible from the direct light of the sun, and also from the light of the external air. No person however has hitherto noticed such an appearance: although many observers attended particularly to it, in the eclipse of 1748 , in consequence of M. De L'isle's remarks. Should the moon in such case ever be visible, it would enable us to determine with greater accuracy the commencement of any solar eclipse $\uparrow$ :

During the progress of the eclipse it would be desirable to ascertain the degree of cold and obscurity caused by the diminution of the sun's rays: for which purpose, preparations should le made beforehand, in order that no time be lost during the period of the eclipse. The variations in the thermometer and barometer may be easily roted down without interrupting the astronomical observations. The rapid change in the temperature of the air may cause a hurricane of wind, (together with rain or snow) as was observed about the middle of the eclipse by $\mathrm{Mr}$. Maclaurin in 1737; and by Le Monnier in 1748. Mr. Short says that (in the eclipse of 1748) "we did not at all perceive or feel any greater degree of cold, during the eclipse, than we felt before it began." But M. Cassini De Thury, who went with the king of France to Compiegne to observe this eclipse, and where it was only $9 \frac{\mathrm{I}}{2}$ digits, says they experienced a considerable degree of cold at the time of the middle of the eclipse; the ther.

* Mem. dê l'Acad. Roy. des Sciences, 1748, page 56.

+ It must be evident to the practical astronomer, that if the moon ware really visible in such cuses, she would also be frequently visible at the conjunctions, when no eclipse took place. M. De Lisle's suggestion arose from a remark made by $M$. Cassini on a luminous ring which was seen to surround Mercury in its passage across the sun's disc in the year 1736, and which continued for 6 or 7 seconds after Mercury was entirely off the suin's disc,-See Mem. de l.Acat. des Sciences for 1736 , page 373 . 
mometer however fell only $2 \frac{1}{2}$ degrees: and the Abbé Nollet found that his burning-glass was then as powerful as before the eclipse began. M. De L'isle, likewise, who observed this eclipse at the Luxembourg, remarks that the thermometer did not indicate any increase of cold caused by the eclipse, although he and many other persons experienced it soon after the middle of the eclipse*.

In the eclipse of 1737 Maclaurin observed that a burningglass which kindled tinder and burnt cloth towards the end of the eclipse, had no effect during the existence of the annulus, nor for some time before and after it. He likewise remarked that " during the appearance of the annulus, the direct light of the sun was still very considerable: and that although some places, that were shaded from his light, appeared gloomy, yet that the day light was not greatly obscured." He adds that many persons, about the middle of the annular appearance, although not short-sighted, were unable to discover the moon upon the sun when they looked without a smoked or coloured glass $\uparrow$. Nevertheless Venus and some other stars were visible at the same time: and Venus continued visible even after the annulus was dissolved. Venus was also seen in the eclipse of 1748 , but it does not appear that any other star was then visible.

If the diminution of light should be considerable (which there is not much reason however to suspect $\ddagger$ ), Mercury, Venus, and Mars, together with some of the principal fixed stars may be visible to the naked eye. Mercury, if visible, will be seen about $18^{\circ}$ to westward of the sun, nearly in conjunction with Regulus :

* In the total eclipse of 1724 the thermometer had fallen only two degrees at the time of the middle of the eclipse. This is the more remarkable as the eclipse took place late in the afternoon of the $22 \mathrm{~d}$ of May, at which time we might presume that the atmosphere would be gradually becoming more cool. The total darkness took place at $6^{\mathrm{h}} \cdot$ 48 $^{\prime}$. P.M.

+ M. Le Monnier mentions the same thing of himself in the eclipse of 1748.

$\ddagger$ In the annular eclipse of 1764 an ignorant country clergyman alarmed the people of France by announcing that there would be total darkness during the existence of the annulus : and the Royal Academy of Sciences at Paris thought proper to give this report a formal contradiction. It is well known however that the smallest ray of light from the sun would prevent such a phæenomenor; as I have shown more at length in my paper " On the solar eclipse which is said to have been predicted by Thales," inserted in the Phil. Trans. for 1811 , part ii. page 220.

I shall here take the opportunity of correcting a typographical error in that paper; where, in page. 240 , line 22 , "three degrees" should be " three minutes." Since the publication of that paper, I find that the Bureau des Longitudes in France have printed a Supplement to M. Burgh's Litnar Tables, wherein the mean epoch and mean motion of the Supplement of the Node are considerably altered; so as to bring the latitude of the moon within the limits which I there suggested. 
Venus will be about $41^{\circ}$ to westward of the sun*: and Mars about $35^{\circ}$ to eastward of the sun, not far from Spica Virginis. The observer should also look out for any comet which may be visible during this eclipse; and be prepared to measure its distance from the sun or a principal fixed star.

As many persons may be so situated as not to be able to procure any dark coloured glass, for the purpose of viewing the sun, I shall conclude this memoir by inserting Dr. Maskelyne's method of smoking glasses, which he published in the Nautical Almanac for 1769, in his Instructions relative to the observation of the transit of the planet Venus over the sun's disc in that year.

"Dark glasses should be used to defend the eye from the intensity of the sun's light. Transparent glasses, smoked cver the flame of a candle or lamp, will give a more distinct and agreeable vision of the disc of the sun than any tinged or coloured glasses will do. Provide two pieces of glass of convenient length, not too thick (the common crown glass, used for windows, will do as well as any), wipe them clean and dry. Warm them a little by the fire (if the weather be cold) to prevent their cracking when applied to the flame of the candle : then draw one of them gently, according to its whole length, through the flame; and part of the smoke will adhere to the glass. Repeat the same operation, only leaving a little part at one end now untouched; repeat the operation, leaving a further part at the same end untouched, and so each time leave a further part of the same end untouched, till at last you have tinged the glass with several dyes, increasing gradually in blackness from one end to the other. Smoke the other glass in like manner; and apply the two glasses, one against the other, only separated by a rectangular border, cut of brass or card paper, the smoked faces being opposed to each other, and the deepest tinges of both placed together at the same end. Tie the glasses firmly together with waxen thread, and they are ready for use. The tinge at one end should be the slightest possible, and at the other end so dark that you eannot see the candle through it. By this contrivance, applied between your eye and the sun, you will have the advantage not only of seeing the sun's light white, according to its natural colour, and his image more distinct than through common dark glasses, but also of being able to intercept more or less of his light as you please, and as the clearness or thickness of the air requires it, hy bringing a darker or lighter part of this combined

* In the total eclipse of 1715 , Venus was seen when only 9 digits were eclipsed : but she was not seen at Compiegne in the eclipse of 1748 , although the digits eclipsed were $9 \frac{7}{2}$ : in the eclipse of 1724 however she was distinctly visible when only 6 digits were eclipsed. This is not remarkable, as she is, in some situations, visible even at mid-day. 
dark glass before your eye: which will be a great convenience at all times, but particularly when the brightness of the sun is liable to sudden changes from flying clouds."

I shall merely add, that it is to be hoped the sovereigns of the different provinces and states, mentioned in this memoir (p.91), will encourage persons from the neighbouring countries to enter and observe this eclipse : and that the love of science will induce them to prevent such persons from being subject to any tarif, or vexatious delay at the Custom-house, on account of any astronomical or philosophical instruments which they may take with them for the purposes of observation.

XIIL. On certain fraudulent and poisonous Sophistications. By Mr.FREDRICK ACCUM*.

\section{Counterfeit Pepper.}

$\mathbf{B}_{\text {Lack Pepper is the fruit of a shrubby creeping plant, which }}$ grows wild in the East Indies, and is cultivated, with much advantage, for the sake of its berries, in Java and Malabar. The berries are gathered before they are ripe, and are dried in the sun. They become black and corrugated on the surface.

That factitious pepper-corns have of late been detected mixed with genuine pepper, is a fact sufficiently known + . Such an adulteration may prove, in many instances of household ceconomy, exceedingly vexatious and prejudicial to those who ignorantly make use of the spurious article. I have examined large packages of both black and white pepper, by order of the Excise, and have found them to contain about 16 per cent. of this artificial compound. The spurious pepper is made up of oil cakes (the residue of lintseed, from which the oil has been pressed), common clay, and a portion of Cayenne pepper, formed in a mass, and granulated by being first passed through a sieve, and then rolled in a cask. The mode of detecting the fraud is easy. It is only necessary to throw a sample of the suspected pepper into a bowl of water; the artificial pepper-corns fall to powder, whilst the true pepper remains whole.

Ground pepper is very often sophisticated by adding to a portion of genuine pepper, a quantity of pepper dust, or the sweepings from the pepper warehouses, mixed with a little Cayenne pepper. The sweepings are known, and purchased in the market, under the name of $P$. D. signifying pepper dust. An in-

* From Treatise on Adulterations of Food and on Culinary Poisons.

+ Thomson's Annals of Chemistry, 1816; also Repository of Arts, vol.i. $1816, \mathrm{p} .11$. 